\title{
Analysing the defects of the Lisbon Ring Expressway bridges
}

Received (in revised form): 18th January, 2004

\section{Jorge de Brito}

graduated in civil engineering and received his masters and doctorate degrees at IST-Technical University of Lisbon, Portugal, where he is an associate professor. He is a member of the International Association for Bridge and Structural Engineering (IABSE) as well as several reputed national engineering societies. His research work deals with deterioration, rehabilitation and management of concrete structures.

\section{Fernando A. Branco}

is an American Concrete Institute (ACI) member and full professor of civil engineering at ISTTechnical University of Lisbon, Portugal. He is Vice-Chairman of the IABSE Commission on 'Maintenance of Structures', Consulting Member of ACI Committee No. 343 on 'Evaluation of Concrete Bridges' and member of the Canadian Society of Civil Engineers (CSCE). He is a national representative for the European Permanent Committee for Experimental Mechanics (PCSA). His primary research interests deal with the behaviour of bridges and other public works.

\section{José Roberto dos Santos}

is a PhD student at IST, where he received his masters degree in structural engineering. His research work deals with the evaluation of concrete structures, in situ testing and construction materials recycling.

\begin{abstract}
As well as being the basis of the maintenance of bridges, bridge inspections allow conclusions to be drawn relative to their design, construction and service stages. An inspection campaign conducted on the bridges of the Lisbon Ring Expressway, the road with the highest traffic volume in the Lisbon metropolitan area, is described in this paper (comprising the appraisal of defects, the measurements made (mostly in terms of sclerometer readings) and carbonation depths) as well as the main conclusions that were drawn from the results. It is concluded that such periodic inspection procedures are a reliable tool for following the degradation of concrete bridges in such aggressive environments as heavy traffic urban areas.
\end{abstract}

\section{Keywords:}

concrete bridges, periodic inspections, in situ measurements, degradation appraisal

\section{INTRODUCTION}

Road bridges in densely populated areas are subject to a wide range of aggressive agents and situations potentially conducive to the development of defects, which may or may not be of a structural nature. From the very 
beginning, bridge construction has to adhere to a timetable that frequently does not allow quality control of the materials and building methods used. Added to the usual atmospheric aggressive agents (rain water, atmospheric $\mathrm{CO}_{2}$ and others) there is pollution derived from intense car traffic. Finally, that same traffic, often represented by either very heavy vehicles or light ones circulating at an excessive speed, is the main reason for the precocious degradation of a number of the bridge components (structural joints and bearings, among others).

This paper presents the main defects found in a series of bridges belonging to the Lisbon Ring Expressway, inspected by ICIST researchers at the request of the Lisbon Accesses Project Direction (DPAL) of the Lisbon City Council (CML) in the period from April 1997 to May 1998. The work undertaken consisted of a detailed visual observation of all the structures as well as the implementation of a number of tests and measurements. The defects detected were the subject of a critical analysis, at the construction elements level, from which it was attempted to draw conclusions concerning the design of those same elements in future structures. The question of the carbonation of the structural elements (in almost every case in exposed concrete) was also the subject of some consideration based on the inspection results obtained.

\section{BRIDGES UNDER ANALYSIS}

Bridges' structural type The bridges that were inspected - all constructed of reinforced concrete and, in some cases, also prestressed - all belong to the Lisbon Ring Expressway, and their chronological inspection sequence was as follows:

1. Ralis Viaduct (No. 11-7A)

2. Fonte Nova Viaduct (No. 7-3A)

3. da Luz Stadium Viaduct — Descending branch (No. 8-3A)

4. da Luz Stadium Viaduct - Ascending branch (No. 8-3B)

5. Estrada da Luz Viaduct (No. 8-4A)

6. Avenida Padre Cruz Viaduct (No. 8-5A)

7. Estrada das Amoreiras Viaduct (No. 8-5C)

8. Rotunda do Aeroporto Viaduct - Access to the Ring Expressway (No. 9-6A)

9. Rotunda do Aeroporto Viaduct in the Avenida das Comunidades Portuguesas (No. 9-6B)

10. Avenida de Berlim Viaduct (No. 9-6C)

11. Viaduct of the Ring Expressway branch (next to the Avenida Dr. Alfredo Bensaúde) (No. 10-7A)

12. Campo Grande Viaduct (No. 8-5B).

In terms of global structure description, the bridges inspected cover a wide range of solutions, such as:

- bridges 1 and 9, with three spans, are classical slab over beams solutions, longitudinally prestressed, simply supported in V-shaped columns with deep foundations; 


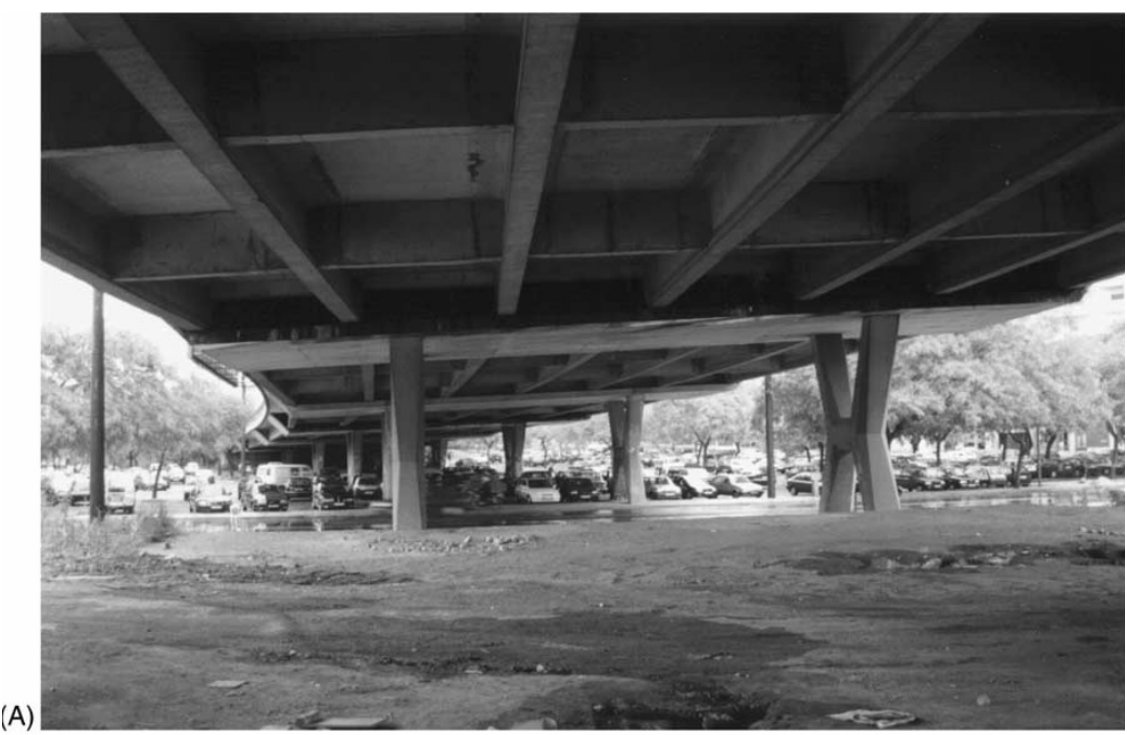

(B)

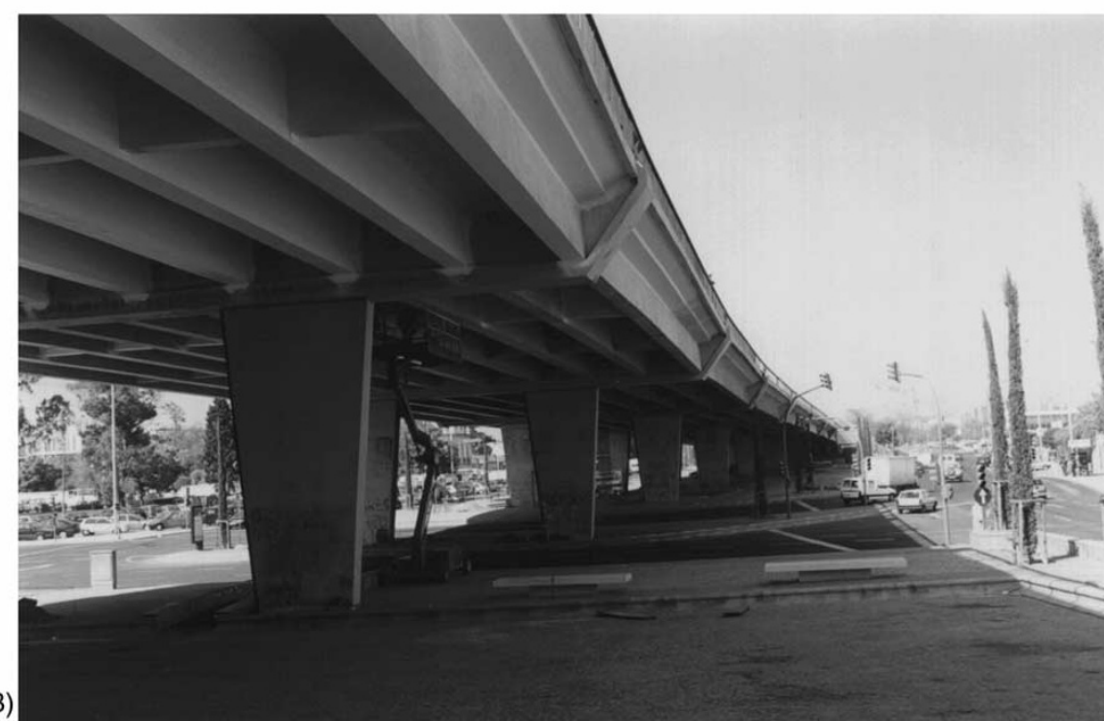

Figure 1: Fonte Nova Viaduct (top) and Campo Grande Viaduct (bottom)

- bridge 2, with seven simply supported spans, is also a slab over beams solution (top of Figure 1), longitudinally and transversally prestressed, supported by X-shaped columns, connected by caisson transverse girders, with deep foundations and semi-buried abutments;

- bridges 3 and 4 are classical frame slabs: walls (with two and one span, respectively), with presumably shallow foundations;

- bridges 5 and 7, with one simply supported span are slab over beams solutions, longitudinally prestressed, with abutments of plain concrete and reinforced soil, respectively, and shallow foundations;

- bridge 6 , with three spans of which the middle one is simply supported, is a slab over beams solution, longitudinally prestressed, supported by inclined columns, with shallow foundations and semi-buried abutments; 
- bridge 8 , with one span, is a frame of slabs over beams (longitudinally prestressed): columns/bearing walls, with deep foundations;

- bridge 10, with three spans, is a slab over beams columns solution, longitudinally prestressed, simply supported by columns, connected at the top by a transverse girder, with deep foundations and semi-buried abutments;

- bridge 11, with three spans, is a classical continuous slab solution, presumably longitudinally prestressed, connected to column walls, with presumably shallow foundations and abutments with top and side walls;

- bridge 12, with 12 spans, is a slab over beams solution (bottom of Figure 1), longitudinally prestressed, supported by column walls, connected by transverse girders inverted and T-shaped, with shallow foundations and abutments with top and side walls.

For most of the bridges, but not all, CML made the projects available, thus facilitating the perception of their structural designs.

\section{DEFECTS ANALYSIS}

\section{Description of the defects detected}

Before doing anything else, it is important to define clearly the range of the inspection campaign to be described here. The main purpose was to detect defects of a structural or non-structural nature, however, leaving aside a structural global evaluation of the bridges. In the same way as for a structural project, drawings were used when available, but solely for the purpose of better guidance of the inspection works. In this respect, one of the first conclusions that could be drawn concerned the usefulness that an analysis of elements before an inspection really represents.

In a simplistic way, the defects were divided into three separate groups:

\section{Defects frequency}

- design, construction or structural behaviour related;

- durability related, frequently with structural consequences;

- non-structural, related to current maintenance (non-structural elements).

A statistical appraisal of the variety and frequency of the defects detected was performed. Table 1 globally summarises this statistical approach.

\section{Lessons to be learned}

The first conclusion drawn from this appraisal was the absolute need for standardisation of the in situ procedures. To that end, the use of inspection checklists, in which the main expected defects were written down, became indispensable, as did a previous knowledge of the classification system of the different defects (frontier cases are very frequent but the classification is not independent of the extension and degree of degradation of the defects). The fact that some very current defects are almost absent from Table 1, such as those related to the bearings, is explained by the fact that they were frequently made of lead and positioned in such a way as to make inspection very difficult. 
Table I: Defects detected in the inspection of the Lisbon Ring Expressway bridges

\begin{tabular}{|c|c|c|}
\hline Type & Description & Frequency $(\%)$ \\
\hline a) & I. Cracking in the abutments' & 83 \\
\hline a) & 2. Beams/columns damaged by vehicle impacts & 67 \\
\hline a) & 3. Columns blocked by the pavement/perrés & 33 \\
\hline a) & $\begin{array}{l}\text { 4. Inclined columns (with crushed joints or } \\
\text { deteriorated bearings) }\end{array}$ & 17 \\
\hline a) & $\begin{array}{l}\text { 5. Crushing of the concrete near the abutments } \\
\text { (edge beams and/or slab) }\end{array}$ & 33 \\
\hline a) & 6. Cracking of the slabs and/or beams & 25 \\
\hline a) & $\begin{array}{l}\text { 7. Excessive deformation/vibration (caused by vehicles) } \\
\text { of the deck }\end{array}$ & 17 \\
\hline a) & 8. Non-existence of the transition slab & 17 \\
\hline b) & 9. Stalactites under the deck & 25 \\
\hline b) & 10. Drainage over elements near the gargoyles & 17 \\
\hline b) & II. Joints deteriorated or open and with infiltrations ${ }^{2}$ & 83 \\
\hline b) & 12. Concrete spalling due to corrosion & 75 \\
\hline b) & 13. Concrete spalling due to bonfires & 25 \\
\hline b) & 14. Generalised corrosion & 17 \\
\hline b) & I5. Localised corrosion & 83 \\
\hline c) & 16. Damaged $3 /$ nonexistent hand railings & 42 \\
\hline c) & 17. Deteriorated hand railings ${ }^{4}$ & 92 \\
\hline c) & 18. Deteriorated/inefficient drainage system & 50 \\
\hline c) & 19. Infiltrations at the abutments & 83 \\
\hline c) & 20. Accumulation of debris/vegetation & 75 \\
\hline c) & 21. Deteriorated acroteria & 58 \\
\hline c) & 22. Deteriorated wearing surface (by the joints) & 67 \\
\hline c) & 23. Slopes with excessive settlement and/or vegetation & 33 \\
\hline c) & 24. Deteriorated/nonexistent sidewalks and curbs & 25 \\
\hline c) & 25. Damaged traffic barrier wall & 25 \\
\hline c) & 26. Broken edge beams, in risk of falling down & 17 \\
\hline c) & 27. Deteriorated lighting system & 8 \\
\hline
\end{tabular}

\section{Durability defects}

From an analysis of Table 1, it can be seen that the most frequent defects are durability related or non-structural. The non-structural defects are due, in most cases, to the irregularity with which inspections are made and the reduced maintenance of the bridges. Inspections of a visual nature must be made frequently, periodically and, while they occur, some simple current maintenance works ought to be carried out, thus avoiding defects such as numbers 20,23,24, 25 and 27. Concerning some of the defects listed, a more detailed analysis is now presented.

The abutments are one of the elements where defects are most frequently found, as illustrated by defect numbers 1 and 19 (top of Figure 2) and, very often, they are frequently associated with defects such as numbers 11, 18 and 20. In general, these defects are due to the following factors which ought to be eliminated: the inadequacy of the abutment foundations, the nonexistence of enough horizontal reinforcement to control cracking, the use of concrete of a worse quality than the rest of the structure, the absence of waterproofing and/or drainage behind the abutments, and the debris accumulated by the bearings. The factors associated with the deck drainage system and its joints will be referred to later in this paper. It must be stated that 

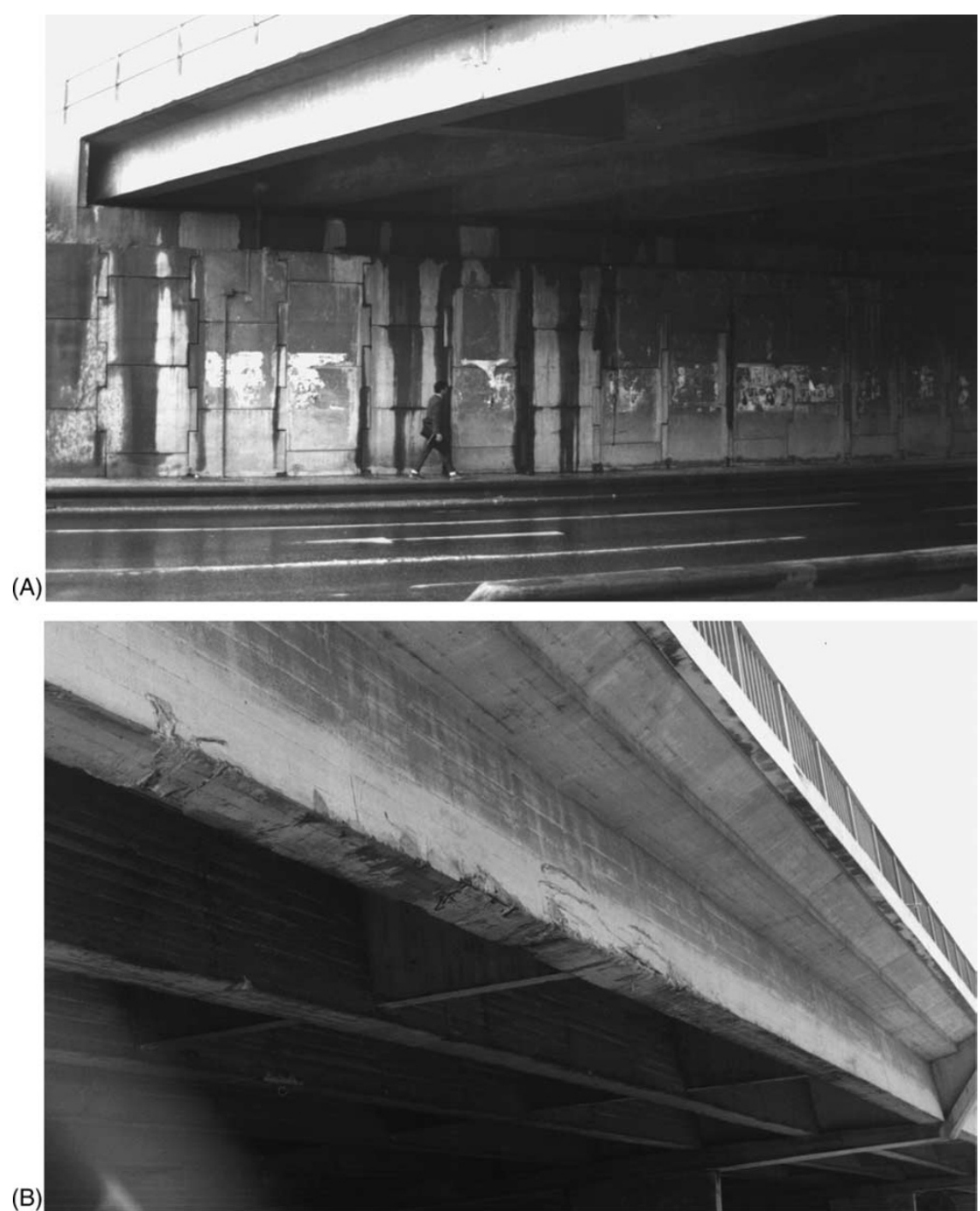

Figure 2: Draining of water in an abutment surface (top) and signs of vehicle impacts in a beam (bottom)

defects number 5 (bottom of Figure 2) and 26 also can be associated with foundation problems of the abutments, even though they can result from other causes.

Another aspect that occurs with an unexpectedly high frequency in Table 1 is the impact of vehicles (defect number 2 - bottom of Figure 2), especially in the beams, naturally connected with a lack of proper vertical clearance. This is sometimes due to the non-compliance of bridge users with the established laws (often correctly sign posted) or to the lack of efficiency of the dissuasive means. It has also been found in situ, however, that the successive asphalt repavements under the bridges and their deficient layout give rise to such situations. Therefore, an increase of the present minimum vertical clearance by $0.50 \mathrm{~m}$ was recommended.

The blocking of the columns by the pavements and/or perrés (defect number 3), even though not very frequently occurring, could easily be 


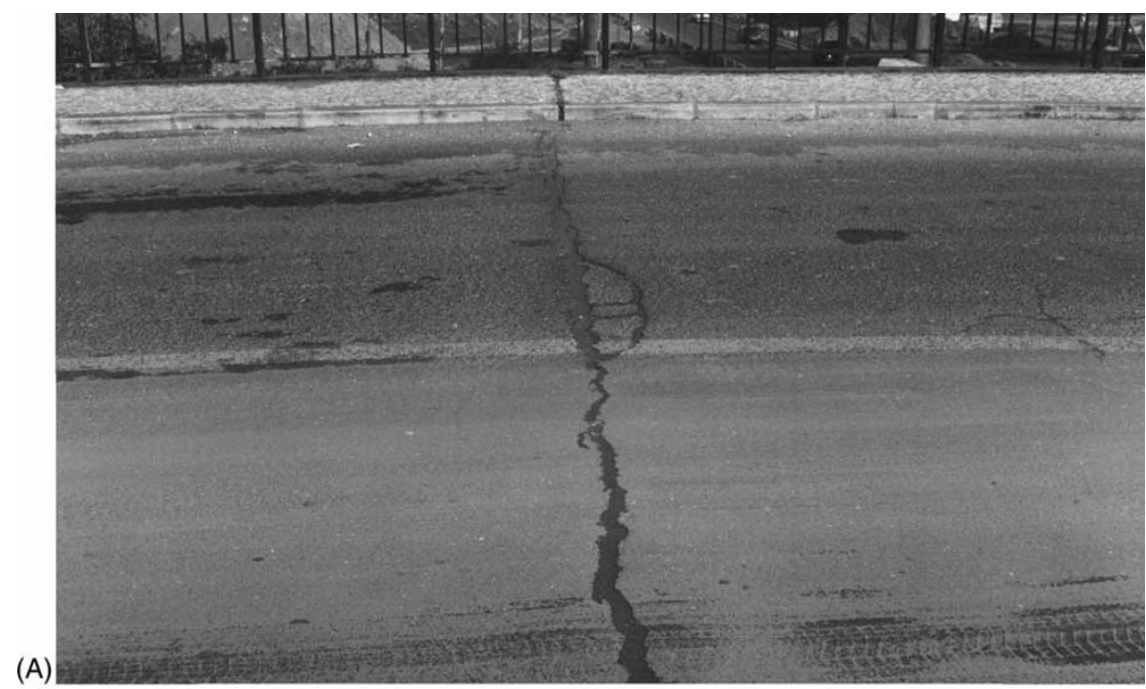

\section{The drainage problem}

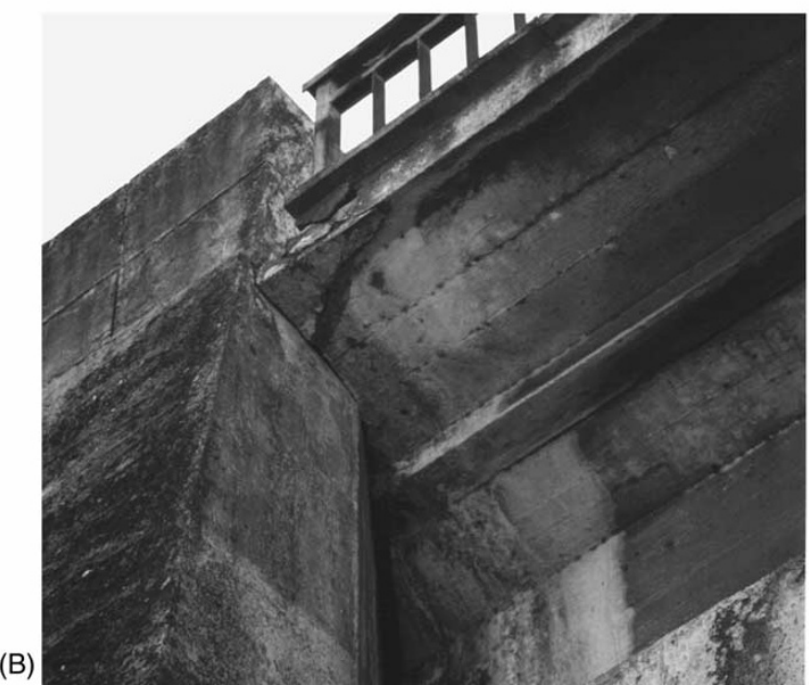

Figure 3: Deterioration of the asphalt over the abutment joint (top) and an edge beam crushed against the abutment due to a rotation of the deck in a horizontal plane (bottom)

eliminated by designing joints around the columns at that level. It must be remembered that this situation can lead to non-predicted damages in the columns when a seism occurs.

The drainage system, when deteriorated or nonexistent (defect number 18), was directly or indirectly responsible for a number of other defects: numbers $9,10,12,14$ and 15 . Very frequently associated with the question of the structural elements' reinforcement corrosion was the absence, inadequacy or deterioration of the waterproofing membrane of the deck. Drainage and waterproofing were responsible for defects present in all the bridges inspected and, undoubtedly, caused the most frequent problems. Other factors, such as the deficient quality of the concrete and the insufficient cover of the reinforcement, also contribute to reinforcement deterioration. In new bridges, it is proposed that a higher quality level of 


\section{Joints and secondary elements}

drainage and waterproofing should be demanded, as well as compliance with the rules governing the design with durability of reinforced concrete structures (ENV 206).

Bridge joints often reveal themselves as a potential source of trouble, being one of the elements with less durability. Therefore, whenever possible, it is recommended that their number is minimised (monolithic solutions are preferable to simply supported ones). When joints must be used, their drainage system must be designed and kept functional (the water must be drained to outside the construction perimeter in order to prevent the settlement of the slopes (defect number 23) and their design must avoid the existence of loose parts or their filling up with asphalt (which tends to deteriorate - defect number 22 - top of Figure 3).

Among the most frequent defects, those related to the hand railings (defects number 16 and 17 and, indirectly, 26) were found, resulting from several causes: bad design, lack of maintenance (replacement of damaged elements and repainting of metallic elements), use of inadequate materials (reinforced concrete, generally of a low resistance and unpainted, is not adequate in this type of element, due to the small cross-sections involved, the low cover of the reinforcement and the aggressiveness of the environment - bottom of Figure 4) and others.

The acroteria have no structural importance, and are very often made of brick masonry. As they are subject to frequent dry-wet cycles and great temperature changes, even when made of reinforced concrete, they very often present advanced deterioration. Therefore, it is recommended that they should be painted and significant reinforcement cover depths should be adopted.

Finally, it is frequent to detect the use of the space under bridges by homeless people. This is a serious social problem in urban viaducts, which cannot be solved by the entities that own the bridges and causes several problems: defect numbers 13 (top of Figure 4) and 20. Besides the implementation of an efficient police vigilance system, bridges must be designed in order not to propitiate such situations.

\section{SCLEROMETER CAMPAIGN}

\section{Description of the test: Range and validity}

Testing by sclerometer

In 11 of the 12 bridges, a sclerometer campaign was implemented. This is a non-destructive in situ test that allows the estimation of the resistance of the superficial concrete. It is based on an empirical relation established between the hardness of the concrete and its resistance, in which the rebound of a calibrated mass, compressed against the concrete surface through a spring that is afterwards released, is measured. The displacement of the mass indicates the sclerometric factor $N$, related to the average compression resistance of the concrete $f_{c m}$.

The results of this test are influenced by a number of parameters that include the types of cement and aggregates, the humidity, the surface irregularities, the surface carbonation etc. Therefore the test must be used with some caution and the recommendation of making at least ten 
measurements for each testing site. The test is indicated mostly for comparative studies of concrete in several different areas of the same structure.

Since the number of sites analysed in each bridge was not, in general, sufficient to validate statistically the conclusions of a numerical nature presented below, these must be accepted with some reservations. Nevertheless, they allow an understanding of certain tendencies, which have since been observed in test campaigns at other bridges.

\section{Results analysis}

It must be stated that, out of the 11 bridges, the plans or any drawings were unavailable for four of them (36 per cent). Based on the plans available, it was possible to verify that, in most cases, the following concrete resistance classes were previewed for the different structural elements:

- in the superstructure (slabs, beams and columns), C30/37 in general, probably C16/20 in columns in frames (bridges 3 and 4) and exceptionally $\mathrm{C} 35 / 35$ (bridge 5);

- in the abutments, $\mathrm{C} 20 / 25$ to $\mathrm{C} 30 / 37$ (the latter being the most frequent);

- in the foundations, C16/20; exceptionally C30/37.

\section{Concrete strength results}

Phenolphtalein testing
The in situ results, with all the reservations presented above and for a variation coefficient $\delta$ considered equal to 15 per cent (the value recommended in most references on the subject for current concrete), in most cases, indicate an additional resistance reserve (to be expected in well-built structures):

- in the superstructure, in general $\mathrm{C} 30 / 37$ to $\mathrm{C} 45 / 55$ and even more; for bridges 3 and 4,C12/15 to C16/20; however, because of lack of access, it was not possible to analyse the superstructure of some of the bridges;

- in the abutments, the results varied greatly between C16/20 and C45/55, and a decrease in resistance was detected in two of the bridges;

- the foundations, because of lack of access, were not analysed.

Possibly because of the greater quality control normally associated with the construction of bridges, only sporadic cases, statistically without significance, were detected of heterogeneities at the level of the resistance of the same type of structural element within the same bridge.

It was verified that the few situations of non-conformity tended to occur more in the lower project resistance classes, associated with less execution and control quality, and in elements such as the abutments and, perhaps, the foundations. The results presented here indicate the obvious usefulness of this test in the inspection campaign.

\section{CARBONATION MEASUREMENT CAMPAIGN}

\section{Description of the test: Range and validity}

Concrete is typically an alkaline material $(\mathrm{pH} \approx 12.5)$. Due to the penetration of $\mathrm{CO}_{2}$ (atmospheric or contained in the exhaust gases from 
(A)

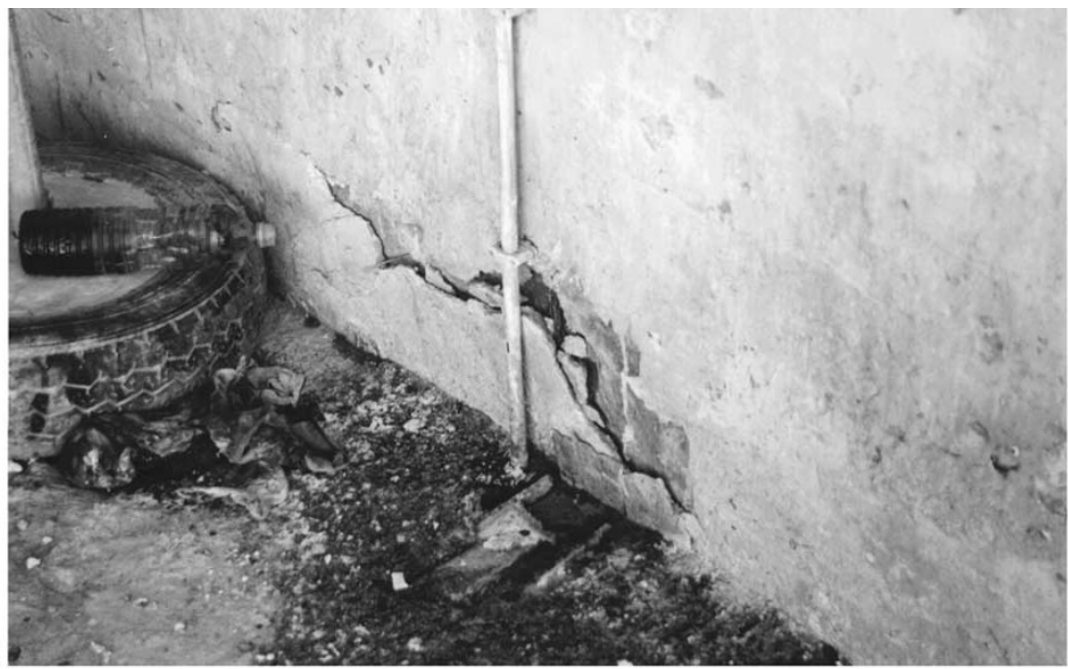

(B)

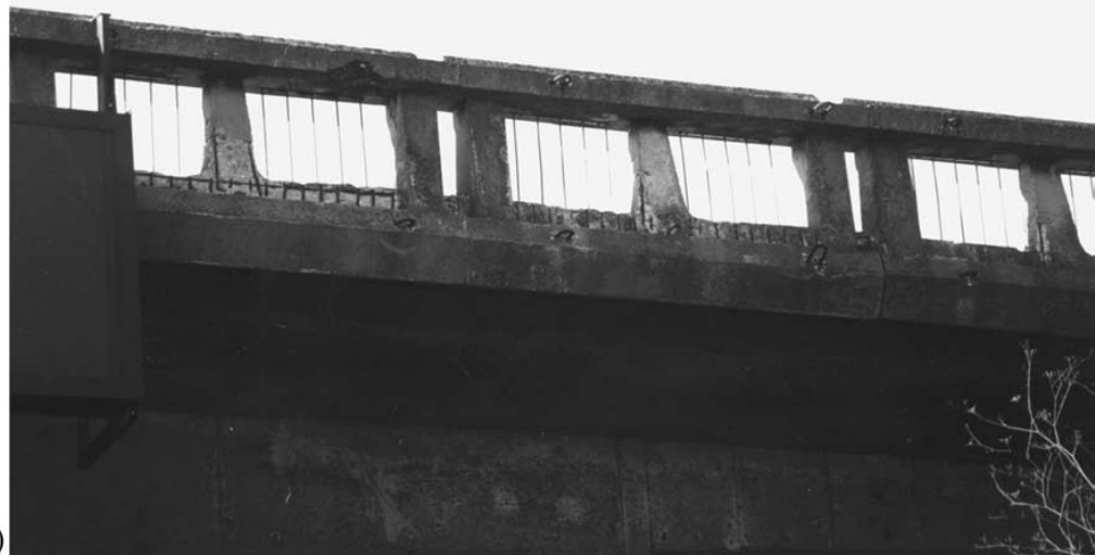

Figure 4: Concrete spalling due to bonfires (top) and hand railings of immensely deteriorated reinforced concrete (bottom)

the vehicles) through its surface, carbonic acid can be created, thus neutralising the alkalinity of the concrete. In this process of carbonation, if the $\mathrm{pH}$ around the reinforcement goes below a value of about 9, corrosion can be initiated as long as oxygen and humidity are present. The depth of the carbonation front (usually abbreviated to carbonation depth), corresponding to the $\mathrm{pH}$ limit referred to above, can be obtained easily by spraying a recently spalled area with a product based on phenolphtalein that, for $\mathrm{pH}<9$, changes from rose-coloured to colourless (at the surface).

In order to validate these measurements statistically, the number generated generally had to be higher than that used in the bridges inspected in this campaign. On the other hand, the carbonation front is sometimes very irregular, thus making it difficult to interpret the in situ results. The depassivation of the reinforcement also can occur due to chloride penetration, a situation not expected in this particular campaign, 


\section{Reinforcement cover results}

\section{Carbonation depth results}

unless it was locally. Finally, the existence of infiltrations (generally giving rise to very fast corrosion rates) 'masks' the results of this test because $\mathrm{CO}_{2}$ is lixiviated, making the results on those areas not valid for comparison.

\section{Results analysis}

As stated above, of the 11 bridges on which this test was performed, plans were not available for four of them. In the remainder, the values proposed for the reinforcement cover also were not available (all the projects had, at the inspection date, around 25 years, with a single exception). Therefore, the values presented below were obtained in situ (with all the irregularities resulting from the building process) and have a poor statistical validity (furthermore, some measurements were not made due to lack of access).

- In the abutments, the cover depths measured varied between $18-40 \mathrm{~mm}$, corresponding to values proposed in the project of $25-30 \mathrm{~mm}$.

- In the columns, the values registered varied between $22-40 \mathrm{~mm}$ (longitudinal bars), corresponding to project values probably of the same scale.

- In the beams and transverse girders, cover depths of 13-20 mm were registered in stirrups and $23-35 \mathrm{~mm}$ in longitudinal bars (corresponding to probable project values of $15-20$ and $25-30 \mathrm{~mm}$, respectively).

- Finally, in the slabs, the values registered were from $14-37 \mathrm{~mm}$, corresponding to average project values of $15-25 \mathrm{~mm}$.

Concerning these values, the most conspicuous fact is that they are, in light of present state-of-the-art theory and the code limits concerning durability, deficient by at least $10 \mathrm{~mm}$. The need to preview adequate reinforcement cover depths has been given some emphasis already.

As a function of the type of structure analysed, the values registered for the carbonation depth were the following:

- in the abutments, between $5-40 \mathrm{~mm}$, which shows a great variability, even though the age of the bridges was relatively uniform

- in the columns, $12-32 \mathrm{~mm}$

- in the beams and transverse girders, $10-36 \mathrm{~mm}$

- in the slabs, $10-22 \mathrm{~mm}$.

From these last values, some conclusions can be drawn. First, the greatest variation and scale of the results were obtained, within the same bridge, in the structural elements made of concrete with less quality and resistance (the abutments) and, within the same structural element type, in the bridges in which the project concrete or the results from the sclerometer test were worse. In terms of structural elements, when the quality of the concrete was the same, those with more corners, such as the columns and 


\section{Service life prediction}

the beams/transverse girders, showed higher results than the laminar ones with only one side exposed (slabs and abutments).

The average age of the bridges inspected was 25 years, which, according to a simplified proportionality rule (factor $k$ ) between the carbonation depth, $x$, and the square root of time, $t(x \approx k \sqrt{t})$, corresponds to average values of $k$ of between around 2.4 and 6.0 m year ${ }^{-1 / 2}$. Generally, the reinforcement of the diverse elements of several bridges inspected was achieving the depassivation stage, thus giving rise to the active stage of the corrosion process. As bad exceptions to this tendency, some cases were registered in which the carbonation depth had already gone past the reinforcement level, as well as others in which exterior factors (very porous concrete, infiltrations, water drainage and others) had created precocious corrosion.

In accordance with these observations, the need to enforce the following strategies was made clearer. First, to increase the reinforcement cover proposed in the project. Secondly, to increase the quality control (depth and impermeability) of that same cover. Just as a term of comparison, the increase of the cover from $25 \mathrm{~mm}$ to $35 \mathrm{~mm}$, according to the rule proposed above, increases the depassivation period by 96 per cent.

One last conclusion concerns the evident usefulness of this carbonation test in the evaluation of the durability of the bridges inspected. As a matter of fact, a higher carbonation depth was always correspondent to an increase in all the symptoms associated with corrosion, also allowing the confirmation of the results from the sclerometer test (concrete less resistant $\Rightarrow$ higher depth of the carbonation front). With all the limitations referred to above, this test indicates the expected remaining service life of the existing structures (in terms of reinforcement corrosion promoted by the carbonation mechanism).

\section{OTHER MEASUREMENTS}

Just for the sake of reference, during this test campaign the following measurements were also performed:

- vertical clearance (in order to confirm the project value or when there was no project);

- bearings verticality (abutments, columns and pendulum bearings);

- cracking width of the asphalt pavement;

- vertical deformations in beams (only in those cases in which the structural safety was questionable);

- vibration caused by vehicles (under the same circumstances).

\section{CONCLUSIONS}

It is possible to draw conclusions from frequently implemented bridge inspection campaigns. The campaign described here, which had a strong emphasis on the durability of the constructions, highlighted important 
indications concerning the design, the construction and even the inspection of this type of structure, enunciated throughout the paper.

\section{Acknowledgments}

This paper has been prepared based on a number of reports developed within ICIST/IST by the authors, at the request of the Lisbon Accesses Project Direction (DPAL) of the Lisbon City Council (CML). 